\title{
EL PODER LEGISLATIVO EN LAS PROVINCIAS ARGENTINAS ${ }^{1}$
}

\author{
THE LEGISLATIVE POWER IN THE ARGENTINE PROVINCES
}

Por Cristian Ezequiel González ${ }^{(*)}$

\begin{abstract}
RESUMEN: En el presente trabajo analizaré diversos aspectos del poder legislativo de la provincia de Córdoba (considerando éste ejercido por un órgano) comparando con las otras provincias del país, como así también indicar su diferente organización, sus funciones características y su sistema electoral. Además, mencionaré lo relativo a sus miembros, como son los requisitos de elegibilidad, las incompatibilidades, duración de mandatos, el régimen de suplencias, privilegios, inmunidades, sanción y remoción. También expresaré sintéticamente el modo de funcionamiento del parlamento vinculado con el quórum, clase de sesiones, modo de deliberación, mayorías para la toma de decisiones, sobre la formación y sanción de leyes en la provincia de Córdoba en comparación con el funcionamiento de las legislaturas de otras provincias.
\end{abstract}

PALABRAS CLAVES: Poder Legislativo - Poderes - Provincias

ABSTRAC: In this paper I will analyze various aspects of the legislative power of the province of Cordoba (considering it to be exercised by one body) comparing it with the other provinces of the country, as well as indicating its different organization, its characteristic functions and its electoral system. In addition, I will mention matters relating to its members, such as eligibility requirements, incompatibilities, duration of terms, the system of substitutes, privileges, immunities, sanctions and removal. I will also summarize the way in which the parliament works, related to the quorum, type of sessions, mode of deliberation, majorities for decision making, on the formation and sanctioning of laws in the province of Córdoba in comparison with the functioning of the legislatures of other provinces.

KEY WORDS: Legislative Power - Powers - Provinces

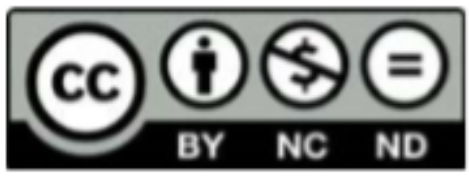

Artículo publicado bajo Licencia Creative Commons Atribución-No Comercial-Sin Derivar. (C) Universidad Católica de Córdoba DOI http://dx.doi.org/10.22529/cdp.2020(8)01

\footnotetext{
${ }^{1}$ Artículo recibido el 14 de mayo de 2020 y aprobado para su publicación el 14 de junio de 2020.

(*) Abogado y notario egresado de la Facultad de Derecho y Ciencias Sociales de la Universidad Católica de Córdoba; Jefe de Trabajos Prácticos interino de la asignatura Derecho Público Provincial y Municipal en la Facultad de Derecho y Ciencias Sociales de la Universidad Católica de Córdoba; Correo electrónico: cristianezequielgonzalez3@gmail.com
} 


\section{FUNCIONES BÁSICAS DEL ORGANO LEGISLATIVO}

\subsection{Función representativa y deliberante}

El profesor Zarza Mensaque considera que los órganos legislativos tienen dos rasgos generales comunes: son, en primer lugar, cuerpos representativos de las diversas corrientes de opinión que integran la sociedad política, y en segundo lugar son cuerpos deliberantes, y además pueden legislar, pero no son los únicos órganos que legislan. ${ }^{2}$

$\mathrm{Al}$ ser cuerpos representativos, cumplen la misión trascendental de ser el órgano ordinario de la intervención de los gobernados en las tares del Estado. La mayoría dialoga con sus líderes por medio de estos organismos que la representan y que en su nombre votan los presupuestos, aprueban las leyes y en general todas las restricciones a los derechos individuales.

$\mathrm{Al}$ ser cuerpos deliberativos, lo típico es el dialogo, la adopción de resoluciones colectivas sobre asuntos de gobierno o de administración a pluralidad de votos y después de discusión pública.

Hay en ello un simbolismo de la acción mayoritaria, en el debate o discusión pública. Todo ello perfecciona al mecanismo representativo, y por otra parte se estima que las disposiciones tomadas por mayoría, son de mayor valor que las de gobierno.

Carl Friedrich sostuvo que la función primordial del parlamento es la representación del pueblo en la defensa y la crítica del gobierno y de su política. ${ }^{3}$

En el artículo 3 de la constitución de Córdoba, consagra que la soberanía reside en el pueblo de la provincia quien la ejerce a través de sus representantes, de lo que resulta esta función de la legislatura.

\section{2) Función de Control:}

Las funciones de control del parlamento adquieren fundamental importancia, si bien tampoco se trata de una actividad reservada única y exclusivamente a este tipo de órgano.

Dentro de este cuerpo colegiado es donde se inserta orgánicamente la estructura del partido político y en donde cumple su rol fundamental la oposición.

Los cuerpos deliberantes son una caja de resonancia de los problemas de la comunidad, pero a su vez como consecuencia del proceso de retroalimentación, es también un órgano conformador de la opinión pública, como así sostiene Linares Quintana.

Por esto, el órgano legislativo es por naturaleza el órgano de contralor y fiscalizador del órgano ejecutivo. Para que exista efectivamente este control es imprescindible contar con una oposición al gobierno, cuya actividad esté garantizada legalmente y con amplias facultades de información.

${ }^{2}$ HeRnAndeZ, Antonio María. Derecho Publico Provincial. Abeledo Perrot, Buenos Aires, 2009. p. 361.

${ }^{3}$ FRIEDRICH, Carl. El Hombre y el Gobierno. Una Teoría Empirica de la Política. Tecnos, Madrid, 1968. p.64 y ss. 
Para que tal control sea efectivo, es necesario que el órgano legislativo pueda con sus propios organismos investigar la conducta de los funcionarios y el desarrollo de la actividad de la administración. Este órgano está previsto en el artículo 103 de la constitución de Córdoba que establece lo siguiente: La Legislatura puede nombrar de su seno comisiones de investigación al solo efecto del cumplimiento de sus fines, las que deben respetar los derechos y garantías personales y la competencia del Poder Judicial. En todos los casos las comisiones deben expedirse ante la Legislatura, en cuanto al resultado de lo investigado.

En cumplimiento de esta función, el órgano legislativo interviene de diversas maneras, según el régimen político, en los procesos de reforma constitucional, y también como tribunal político para hacer efectiva la responsabilidad del gobierno mediante el juicio político.

En la constitución de Córdoba, esta facultad surge de diversos artículos entre los que se encuentra el artículo 101 que otorga la facultad a la legislatura de hacer comparecer a los ministros (como miembros del órgano ejecutivo) al recinto para pedir informes o explicaciones que estimen convenientes. También en virtud del artículo 102 de esta constitución cada legislador puede pedir informes al Poder Ejecutivo por cuestiones de interés público, para el mejor desempeño de su mandato.

También la presente facultad se manifiesta en el artículo 104 de la misma constitución mencionada, en los incisos número 4 (sobre la aprobación de la legislatura relativa a las licencias del gobernador y del vicegobernador para salir de la provincia, cuando las ausencias abarquen un periodo mayor a 15 días), número 33 (autorizar al Poder Ejecutivo a contraer empréstitos).

La doctrina divide entre las constituciones que no han explicitado sus atribuciones, y otras que, si lo han hecho como las constituciones de Buenos Aires, Santa Fe y Mendoza.

Por ejemplo, las Constituciones de Buenos Aires, Mendoza y Tucumán establecen la atribución de su Poder Legislativo de pedir informes tanto al Jefe del departamento de la Administración o responsable de oficinas como a sus ministros. Mientras que Constituciones como las de Santa Fe, Salta, Misiones y Entre Ríos prevén solo la atribución de citar a los ministros.

\section{MODOS DE ORGANIZACIÓN DEL PARLAMENTO}

Según Arturo M. Bas, que a mérito de lo dispuesto en los artículos 5 y 105 de la Constitución Nacional, las provincias pueden a su arbitrio consagrar la organización libremente, adecuándola a la realización de los fines del gobierno publico seccional. Sin perjuicio de esto, Bas entendía que la división de la 
legislatura en dos instancias inducia cierto equilibrio, provocaba una doble discusión, y dificultaba la precipitación en la sanción de leyes ${ }^{4}$.

Rodolfo Berardo sostiene que las provincias, al ser autónomas, no existen razones que las obliguen a la instauración de un organismo bicameral, pues los partidos o departamentos en que se dividen las provincias, son meras divisiones administrativas. ${ }^{5}$

La doctrina considera actualmente los siguientes argumentos a favor de uno y otro sistema:

\subsection{Argumentos a favor del sistema Bicameral ${ }^{6}$ :}

La doble instancia legislativa sirve como un freno para la legislación apresurada e irreflexiva. Una segunda cámara constituida de manera diferente a la anterior tiende a frenar tales tendencias y permite una consideración serena y cuidadosa de los proyectos legislativos.

La cámara única no solo es incapaz de asegurar una legislación acertada y prudente, sino que necesariamente lleva en sí el germen de la tiranía parlamentaria, que es lo más terrible por ser la más irresponsable y poderosa.

La existencia de dos cámaras permite a la segunda, una competencia técnica o de representación de intereses particulares.

En el mismo proceso reformador se ha sostenido que el sistema bicameral ha sido tradicional en nuestro país, tanto en el orden nacional como en el provincial.

La cámara de Diputados es la auténtica representante del pueblo de la provincia, tomada ésta como distrito único. Y el Senado constituye la representación geopolítica provincial. La provincia presenta realidades muy distintas y ellas deben ser plasmadas en una representación diversa dentro de las propias cámaras.

Por otra parte, el sistema bicameral brinda seguridad jurídica, ya que garantiza un mayor estudio de los proyectos por el doble debate, posibilitando el dictado de normas correctas y adecuadas.

La doble cámara trae aparejado el control inter órgano, la existencia de dos cuerpos legislativos evita los abusos y excesos a que solo uno puede abandonarse; la cámara revisora puede siempre servir de freno y control a la iniciadora.

Adoptan este sistema 8 provincias (Buenos Aires, Catamarca, Corrientes, Entre Ríos, Mendoza, Salta, San Luis y Santa Fe).

\footnotetext{
${ }^{4}$ BAS, Arturo. El Derecho Federal Argentino, Nacion y Provincia. Valerio Abeledo, Buenos Aires, 1927. p.245 y ss. 5 BERARDO, Rodolfo. Instituciones del Derecho Publico Provincial, El Federalismo Argentino. Depalma, Buenos Aires, 1981 . p. 46 y ss.

${ }^{6}$ http:/ / launiondigital.com.ar/noticias/132692-pro-y-contra-un-sistema-bicameral-y-unicameral. fecha de consulta: $28 / 10 / 2019$.
} 


\subsection{Fundamentos a favor del sistema unicameral ${ }^{7}$}

La cámara única permite una mayor eficiencia y celeridad al posibilitar la sanción de normas con mayor agilidad, permitiendo al legislador adecuar su gestión a los requerimientos del Gobierno.

Una de las principales críticas que se les efectúa a todos los parlamentos es la lentitud y no la precipitación; añadir un freno complementario agrava el mal que sería necesario corregir. Con normas adecuadas de trabajo interno se asegura toda la reflexión necesaria.

Rechazando el argumento de que la bicameralidad impide las tiranías parlamentarias, se sostiene que en la actualidad el monopolio de las representaciones políticas la tienen los partidos organizados que actúan con férrea disciplina.

El doble examen y los constantes reenvíos de una Cámara a otra, en el procedimiento de formación y sanción de las leyes, traen aparejada una manifiesta lentitud.

La necesidad de un cuerpo colegiado poderoso que esté en condiciones de controlar al Ejecutivo y que nos sea un simple acompañante tardío de las decisiones tomadas por éste.

La necesidad de dotar a la Legislatura de una mejor organización técnica eficiente, sin dobles estructuras, ninguna de la cuales es eficaz.

El menor costo operativo:

La unidad decisional no debilitada por la división en Cámaras y la sencillez que requiere la tarea legislativa, son otras de las razones en favor del unicameralismo.

En Córdoba, a partir del año 2001, se adoptó el sistema unicameral (artículo 77 - Constitución de Córdoba), previa consulta popular sobre esta cuestión, cuyo resultado dotó de mayor legitimidad la reforma de la constitución de ese año. Además, otras 14 provincias más la Ciudad Autónoma de Buenos Aires también adoptan el sistema unicameral (Chaco, Chubut, Formosa, Jujuy, La Pampa, La Rioja, Misiones, Neuquén, Rio Negro, San Juan, Santa Cruz, Santiago del Estero, Tierra del Fuego y Tucumán).

\section{SISTEMA ELECTORAL DEL ORGANO LEGISLATIVO}

Para Dieter Nohlen el sistema electoral es el modo según el cual el elector manifiesta a través del voto el partido o candidato de su preferencia, y según el cual esos votos se convierten en escaños. ${ }^{8}$

\footnotetext{
7 http:/ / launiondigital.com.ar/noticias/132692-pro-y-contra-un-sistema-bicameral-y-unicameral. fecha de consulta: 28/10/2019.

8 https://politicaymedios.net/el-sistema-electoral-nohlen/. fecha de consulta: 28/10/2019.
} 
Cabe mencionar en primer lugar la principal clasificación de sistemas electorales, citando la explicación de Araujo Rentería:

\subsection{Sistema de mayorías o la de representación mayoritaria}

Supone que quien obtiene la mayoría se lleva toda la representación; cuando se va a elegir a un solo representante (circunscripción uninominal) necesariamente se hace uso de éste sistema; también puede utilizarse cuando se va a elegir más de un representante (circunscripciones plurinominales).

\subsection{Sistema proporcional o la representación proporcional}

Es aquella técnica que consiste en que, la lista que obtenga más votos tendrá la posibilidad de ocupar más escaños o puestos, y el que obtenga menos votos, tendrá menos posibilidades de ocupar escaños o puestos. Este sistema es más aplicado en las circunscripciones plurinominales, es decir cuando se tenga que elegir a más de un representante. ${ }^{9}$

En la provincia de Córdoba el Poder Legislativo es ejercido por una legislatura de una sola cámara de setenta miembros (Artículo 77 - Constitución de Córdoba), que se integra de la siguiente forma:

1. Por 26 legisladores elegidos directamente por el pueblo, a pluralidad de sufragios y a razón de uno por cada uno de los departamentos en que se divide la Provincia, considerando a éstos como distrito único.

2. Por 44 legisladores elegidos directa y proporcionalmente por el pueblo, tomando a toda la Provincia como distrito único (artículo 78 - Constitución de Córdoba). ${ }^{10}$

La distribución de estas bancas se efectúa de la siguiente manera:

a) El total de los votos obtenidos por cada una de las listas se divide por uno, por dos, por tres y así sucesivamente hasta llegar al número total de las bancas a cubrir.

b) Los cocientes resultantes, con independencia de la lista de la que provengan, se ordenan de mayor a menor hasta llegar al número cuarenta y cuatro.

c) Si hubiere dos o más cocientes iguales, se los ordena en relación directa con el total de los votos obtenidos por las listas respectivas, y si éstas hubiesen logrado igual número de votos, el ordenamiento definitivo de los cocientes empatados resulta de un sorteo que a tal fin debe practicar el Juzgado Electoral.

\footnotetext{
9 ARAUJO RENTERIA, Jaime. Principios del Derecho Constitucional. Mc Graw Gil, Bogotá, 1999. p. 22 y ss.

${ }^{10}$ http://www.cba.gov.ar/provincia/sistema-de-gobierno/poder-legislativo-y-judicial/. fecha de consulta: 28/10/2019.
} 
d) A cada lista le corresponden tantas bancas como veces sus cocientes figuren en el ordenamiento de las cuarenta y cuatro bancas.

Para esta lista de candidatos a legisladores de distrito único se establece el voto de preferencia, conforme a la ley que reglamente su ejercicio.

El voto de preferencia (implica alterar el orden de las listas de legisladores) no ha sido reglamentado en nuestra provincia.

El profesor Jorge Gentile considera como consecuencia de esto, algunos candidatos que no están en la cúspide de las boletas, son los que terminan siendo los titulares de las bancas que reparte el sistema proporcional. ${ }^{11}$

Desde fines del 2000, con la sanción de la Ley Provincial 8.901 del Cupo Femenino, se ha consagrado el principio de participación equivalente de géneros para la elección de los legisladores que componen la Cámara.

Conforme el Art. 79 de la citada constitución, se proclama legisladores provinciales a quienes resulten elegidos con arreglo al sistema electoral.

Como conclusión, el sistema electoral adoptado por Córdoba es doble, ya que adopta el sistema proporcional cuya fórmula electoral es el sistema d’hondt para elegir 44 legisladores (representación poblacional) y también el sistema de circunscripción y voto uninominal para elegir los restantes 26 legisladores que corresponde a uno por cada departamento (representación territorial).

Este sistema también lo aplican otras provincias como Rio Negro, San Juan y Santa Cruz.

Además, hay que mencionar que otros sistemas electorales han sido adoptados por provincias como es el caso de Entre Ríos y Santa Fe que por su parte adoptaron el sistema mixto mayoritario-proporcional para la elección de diputados (en donde la mayoría de las bancas las obtiene el partido más votado), mientras que en la elección de senadores adoptaron un sistema mayoritario de circunscripción uninominal. La única diferencia que existe entre ambos sistemas es que el santafesino determina una cantidad fija de diputados que le corresponde al partido más votado (veintiocho diputados al partido que obtenga mayor número de votos y veintidós a los demás partidos).

La amplia mayoría de las provincias que adoptan el sistema proporcional establecen un piso electoral que limita la participación de partidos políticos en el reparto de bancas.

Un caso especial es el sistema electoral de la provincia de Buenos Aires que divide su territorio en secciones electorales donde cada una elige una determinada cantidad no uniforme de senadores y diputados (sistema proporcional plurinominal). Además, en los artículos 69 y 75 establecen que la

${ }^{11}$ http://www.profesorgentile.com/n/el-voto-de-preferencia.html. fecha de consulta: 28/10/2019. 
cantidad de diputados y senadores podrán aumentar hasta un número máximo cien y cincuenta respectivamente con el voto de $2 / 3$ de los miembros de cada cámara.

Mismo sistema adoptan provincias tales como: Tucumán, Mendoza y Salta.

En el caso de la provincia de Mendoza la elección de senadores como diputados adoptan el sistema proporcional, dividiéndose la cantidad de cargos a elegir entre 4 secciones electorales. Además, en su constitución establece números mínimos de diputados y senadores a elegir por sección (artículos 68 y 76).

La provincia de Chaco adopta el sistema proporcional para la elección de sus diputados tomándose como distrito único.

\section{ASPECTOS RELATIVOS A LOS LEGISLADORES}

\subsection{Requisitos de elegibilidad}

Todas las constituciones provinciales establecen requisitos en cuanto a la edad, la ciudadanía en ejercicio y la residencia en su territorio.

El artículo 82 de la constitución de Córdoba establece los requisitos que deben cumplir los legisladores y son los siguientes:

A) Haber cumplido la edad de dieciocho años al momento de su incorporación.

B) Tener ciudadanía en ejercicio con una antigüedad mínima de cinco años, para los naturalizados.

C) Tener residencia en la Provincia en forma inmediata y continua durante los dos años anteriores a su elección. A tales efectos no causa interrupción la ausencia motivada por el ejercicio de funciones políticas o técnicas al servicio del Gobierno Federal o de la provincia. Los legisladores de los departamentos deben ser oriundos o tener una residencia no menor a tres años en los mismos.

De modo general, todas las constituciones determinan una edad para acceder a su órgano legislativo. Como antes se indicó la constitución de Córdoba (al igual que la de Mendoza) establece la mayoría de edad mientras que otras constituciones como la de Tucumán, Misiones, Chaco y Entre Ríos exigen la de edad de 25 años. En el caso de las provincias de Buenos Aires y Santa Fe determinan el requisito de 22 años para ser diputados y 30 para ser senadores (al igual que Entre Ríos en cuanto a los senadores). En el caso de Salta establece una edad mínima de 21 años.

También las constituciones establecen un requisito sobre la ciudadanía y residencia, permitiendo ser candidatos tanto los nativos como naturalizados. Así como, por ejemplo, la constitución de Buenos Aires como la de Córdoba y Salta establecen que la ciudadanía mínima exigida es de 5 años, para ser 
diputado o senador en Buenos Aires y Mendoza y legislador en Córdoba. Pero difieren en que la residencia exigida en Buenos Aires es de 1 año mientras que para Córdoba se exige 2 años para los legisladores electos por el sistema proporcional, mismo requisito exige las constituciones de Santa Fe, Mendoza, Entre Ríos y Tucumán. Por su parte Salta establece que la residencia mínima debe ser de 4 años y Chaco de 3 años mismo requisito adopta Córdoba en la elección de legisladores departamentales. La constitución de Tucumán por su parte establece que la ciudadanía mínima debe ser de 2 años mientras que la de Entre Ríos establece que debe ser de 4 años para ser diputado, y de 6 años para ser senador. Las constituciones de Misiones y Chaco establecen que sus representantes o diputados posean una ciudadanía mínima de 4 años.

Un dato relevante a mencionar es que la Constitución de Mendoza en su artículo 66 establece que en ninguna de las cámaras podrá haber más de la quinta parte de sus miembros con ciudadanía legal (no nativo).

\subsection{Incompatibilidades}

El artículo 87 de la constitución de Córdoba establece que el cargo de legislador es incompatible con:

1. El ejercicio de función o empleo a sueldo en el Gobierno Federal, las Provincias o los Municipios, con excepción de la docencia en cargo de dedicación simple, y las comisiones honorarias eventuales para cuyo desempeño se requiere autorización previa de la Legislatura.

2. Todo otro cargo de carácter electivo nacional, provincial o municipal, excepto los de Convencional Constituyente o Convencional Municipal.

3. El ejercicio de funciones directivas o de representación de empresas adjudicatarias de concesiones, licencias o permisos por parte del Estado.

4. El ejercicio de funciones en las Fuerzas Armadas o de Seguridad. Los agentes de la Administración Provincial o Municipal que resulten electos legisladores titulares, quedan automáticamente con licencia sin goce de sueldo por el tiempo que dure su función.

Estas incompatibilidades, se establecen debido a la importancia que configura la función legislativa. Ello reconoce un fundamento ético, material y jurídico. Lo que se pretende es evitar que el legislador, en el ejercicio de su mandato, entre en colisión con intereses particulares en la resolución de los problemas de la provincia, y por otra parte permitirle una dedicación plena a la actividad, que no se obtiene sin la disposición de tiempo suficiente como para lograr esos objetivos.

La mayoría de las provincias han establecido amplias causales de incompatibilidad. Las constituciones de Santa Cruz y Tucumán, no dicen nada en esta materia (solo mencionan la imposibilidad de realizar un empleo nacional, provincial o municipal en simultaneidad con el cargo de legislador). 


\subsection{Duración de mandatos}

El artículo 87 de la constitución de Córdoba establece que los legisladores duran cuatro años en sus funciones y son reelegibles. La Legislatura se constituye por sí misma.

Los legisladores inician y concluyen sus mandatos en la misma oportunidad que el Poder Ejecutivo.

En la mayoría de las constituciones establecen que tanto sus diputados o senadores (si el sistema es bicameral) como sus legisladores duran 4 años, con excepción de los senadores de la provincia de Corrientes que duran 6 años. Lo que diferencia a las constituciones es si la renovación de los mandatos es total (como en Santa Fe), por mitades (como en Salta, Buenos Aires, Mendoza), o por terceras partes (como en Entre Ríos). La renovación de cargos en Córdoba es total.

Mención especial corresponde realizar a la constitución de Tucumán que limita la reelección de sus legisladores a un nuevo periodo consecutivo. Córdoba establece lo mismo, pero en la ley electoral (Art. 166).

4.4. Régimen de suplencias

La suplencia puede ser temporaria o permanente, y están previstas en los artículos 80 y 81 de la constitución de Córdoba que expresan lo siguiente:

Artículo 80: En el mismo acto eleccionario se eligen legisladores suplentes.

En el caso de los legisladores departamentales, producida una vacante, se cubre con su suplente. En el caso de los legisladores electos por distrito único, producida una vacante, se cubre de la siguiente forma:

1. Por los candidatos titulares del mismo género que no hayan resultado electos, en el orden establecido en la lista partidaria en primer término, y luego por los candidatos suplentes del mismo género, en el orden establecido en la lista partidaria.

2. Finalizados los reemplazos por candidatos del mismo género, se continúa la sucesión por el orden de titulares y suplentes del otro género.

En todos los casos, si se agotara la lista de titulares y suplentes, la Legislatura comunica al Poder Ejecutivo para que en forma inmediata convoque a una nueva elección según corresponda.

Artículo 81: En caso de impedimento personal o licencia de un legislador que exceda los treinta días, el cargo se cubre temporariamente conforme a lo establecido en el artículo anterior.

En la gran mayoría se establece la elección de legisladores suplentes junto a los titulares, esto es a los fines de evitar la realización de una nueva elección con el objeto de cubrir la vacante, y como consecuencia generar nuevos gastos y un nuevo clima preelectoral que altere la vida del órgano legislativo. 
En la constitución de Buenos Aires no regula el régimen de suplencias.

\subsection{Prerrogativas e inmunidades}

Los privilegios de los parlamentarios son prerrogativas que gozan los legisladores para el mejor desempeño de sus funciones y les son otorgadas con el objeto de asegurar la independencia y jerarquía del cuerpo, y no el interés particular del legislador. El valor que está en juego es la independencia y seguridad de los miembros de la legislatura, tanto individualmente como del organismo de él.

Están previstos en los artículos 89 y 90 de la constitución de Córdoba que establecen lo siguiente:

Artículo 89: Ningún miembro del Poder Legislativo puede ser acusado; interrogado judicialmente, ni molestado por las expresiones en los medios de comunicación o en cualquier otro ámbito, que en el desempeño de su mandato como legislador, emita en el recinto o fuera de él.

Fenecido su mandato ningún legislador puede ser acusado o interrogado judicialmente, ni molestado por las opiniones que hubiere expresado en el ejercicio de sus funciones. El Tribunal ante el cual se formule la acción judicial contra un legislador relacionada con lo antes mencionado deberá declararla inadmisible, aunque se presente con posterioridad a la finalización de su mandato.

Esta es la denominada por la doctrina como inmunidad de opinión, un privilegio individual, establecido en muchas constituciones provinciales.

Artículo 90: Los candidatos, una vez oficializadas las listas respectivas y hasta ser proclamados los electos, tienen las siguientes prerrogativas:

1. A no ser molestados por las autoridades ni detenidos por opiniones vertidas con motivo de la campaña electoral.

2. A solicitar y recibir información por parte del Poder Ejecutivo.

Además de la constitución de Córdoba, otras constituciones como las de las provincias de Chaco, Santiago del Estero, Buenos Aires y Corrientes extienden este privilegio en favor del candidato a cargo electivo, proclamado por un partido político reconocido.

Varias constituciones provinciales (como, por ejemplo las de Buenos Aires, Rio Negro, Santa Cruz, Corrientes, Tucumán, Entre Ríos, Salta, Misiones y Mendoza) prevén la inmunidad de arresto. La constitución de Córdoba la preveía en el artículo 75 hasta que fuera eliminada en la reforma del año 2.001.

La doctrina también sostiene la existencia de privilegios colectivos (que solo pertenecen al órgano legislativo) como ser considerado juez de las elecciones (indaga sobre la validez de la elección, derechos y títulos de sus miembros). Establecido este privilegio en el artículo 92 de la constitución de Córdoba, y 
también previsto en otras constituciones como la de Mendoza y Corrientes. También prevén la potestad de sancionar a terceros que cometan faltas, solicitar información al órgano Ejecutivo.

\subsection{Modos de sanción, renuncia y remoción}

El artículo 99 de la constitución de Córdoba. Establece que puede, con el voto de los dos tercios de la totalidad de sus miembros, corregir, excluir de su seno a cualquiera de ellos por desorden de conducta en el ejercicio de sus funciones o por indignidad, y removerlo por inhabilidad física o psíquica sobreviniente a su incorporación. En todos los casos debe asegurarse el derecho de defensa y debido proceso. Esta prerrogativa también es prevista en otras constituciones como las de Chaco, Salta, Mendoza, Tucumán y Entre Ríos.

Con respecto a la renuncia, el artículo citado de la constitución de Córdoba. Continúa expresando que para decidir sobre la renuncia que voluntariamente hicieren de sus cargos basta el voto de la mayoría de los miembros presentes.

Se expresa en igual sentido las constituciones como, por ejemplo, de Mendoza, Tucumán, Buenos Aires, Misiones y Entre Ríos. En estas provincias se otorgó en forma expresa a las legislaturas la potestad de controlar la conducta y desenvolvimiento de sus integrantes, corrigiéndolos, sancionándolos y removiéndolos, no siendo necesario para ello de la comisión de un delito. Otras constituciones como la de Corrientes y Chaco establecen la potestad del órgano legislativo de declarar cesante al legislador en caso de ausentismo notorio e injustificado.

\section{FUNCIONAMIENTO DE LA LEGISLATURA}

El derecho parlamentario se trata de un conjunto de disposiciones que regula el funcionamiento de las legislaturas provinciales, sean éstas unicamerales o bicamerales.

Según el artículo 84 de la constitución de Córdoba tiene autoridad máxima en la legislatura siendo el Presidente, quien a su vez es el vicegobernador de la provincia. Sin perjuicio de ello, la legislatura provincial nombra de su seno un presidente provisorio que la preside en caso de ausencia del vicegobernador, o cuando éste ejerce funciones inherentes al Poder Ejecutivo. Este presidente de la legislatura tiene como funciones más comunes la de ejercer la autoridad superior en el gobierno de la legislatura, nombrar el personal de la misma, remover o aplicar sanciones disciplinarias al personal, dirigir la discusión en las sesiones, proponer las votaciones y proclamar los resultados, designar los asuntos que han de integrar el orden del día, mantener el orden en las sesiones. 
En las constituciones que adoptan el sistema bicameral, como Buenos Aires y Santa Fé, establecen que la cámara de diputados será presidida por un miembro elegido en su seno, mientras que el senado será presidido por el vicegobernador. En las constituciones de Misiones y Chaco el presidente de su cámara de representantes o de diputados es elegido directamente por sus miembros.

El quórum es el número requerido de legisladores para que las cámaras puedan constituirse en función y tomar decisiones.

Las constituciones provinciales han dispuesto, que para su normal funcionamiento, la o las cámaras necesitan mayoría absoluta de sus miembros (la mitad más uno de sus miembros), pero se admite que pueda reunirse un número menor para tomar decisiones en contra de los ausentes.

Las sesiones pueden ser de distintas clases:

A. Sesiones Preparatorias: Como su nombre lo indica, tienen por finalidad preparar el próximo período legislativo. Están contempladas en el artículo 22 del Reglamento Interno de la legislatura de Córdoba y su finalidad es la de designar autoridades y funcionarios y fijar los días y horas de tablas de las sesiones ordinarias del siguiente período legislativo.

B. Sesiones Ordinarias: El artículo 96 de la constitución de Córdoba establece que: "La Legislatura se reúne por propia convocatoria en sesiones ordinarias todos los años, desde el primero de febrero hasta el treinta de diciembre...”

Este tipo de sesiones revisten este carácter porque es el período en el que, obligatoriamente, la Legislatura debe sesionar, tratándose todos los asuntos de interés que se presenten.

Por ejemplo, en Santa Fe las cámaras se reúnen en sesiones desde el $1^{\circ}$ de mayo hasta el 31 de diciembre, mientras que en Buenos Aires las cámaras se reúnen desde el $1^{\circ}$ día hábil de marzo hasta el 30 de noviembre. En Tucumán las sesiones ordinarias se realizan del $1^{\circ}$ de marzo hasta el 30 de junio y del el $1^{\circ}$ de septiembre hasta el 31 de diciembre. En Mendoza se efectúan del 1 de mayo al 30 de septiembre.

C. Sesiones Extraordinarias: El artículo 97 de la constitución de Córdoba se refiere a esta clase de sesiones. Son extraordinarias precisamente porque se realizan fuera del período ordinario de sesiones, estando la legislatura en receso.

Se pueden establecer entonces, como principales diferencias que presentan estas sesiones respecto a las ordinarias, las siguientes:

1. Se realizan durante el período de receso legislativo;

2. Poseen un temario de tratamiento acotado, es decir, sólo se pueden considerar los asuntos para los cuales fue convocada; 
3. Pueden ser convocadas por el Poder Ejecutivo o por el Presidente de la Legislatura a solicitud escrita de una cuarta parte de sus miembros, y

4. Los plazos que la Constitución establece, sólo corren para los expedientes incluidos en la convocatoria.

D. Sesiones de Prórroga: El artículo 96 de la constitución de Córdoba, al tratar sobre las sesiones ordinarias, dispone que las mismas pueden ser prorrogadas por el Poder Ejecutivo o por disposición de la misma legislatura. Se advierte entonces que puede suceder que, previo a finalizar el período de sesiones ordinarias, resulte conveniente prolongar su vigencia a fin de concluir el tratamiento de determinados temas.

51. Comisiones legislativas permanentes o de receso:

Estas comisiones elegidas por la legislatura antes de finalizar cada periodo ordinario de sesiones y compuestas por pocos miembros, ejercen la representación del cuerpo durante el receso parlamentario.

Se constituyen en diferentes grupos de trabajo, con temarios y asuntos de una índole específica, conforme la comisión de que se trate, para establecer una especialización temática que asegure el mejor conocimiento y tratamiento legislativo de los proyectos.

Cuando un mismo asunto o tema es común a dos o más comisiones, pueden estudiarlo en forma individual o conjunta, comenzando por aquella que fuera designada como comisión principal, con aviso a las otras. En caso de producirse despacho del proyecto en tratamiento, el mismo debe contar con la aprobación de todas las comisiones intervinientes para que pase a consideración del plenario del Cuerpo.

Procedimiento de formación y sanción de leyes:

1. INICIATIVAS: El artículo 105 de la constitución de Córdoba dispone que los proyectos de ley pueden ser iniciados por los miembros de la legislatura, por el Poder Ejecutivo y por la ciudadanía mediante la "iniciativa popular". Sin embargo, en el mismo texto constitucional se puede advertir que el Tribunal Superior de Justicia también tiene entre sus atribuciones (artículo 166, inciso 5), la de elaborar proyectos de leyes sobre organización y funcionamiento del Poder Judicial, con la única salvedad que debe elevarlos a la legislatura, por intermedio del Poder Ejecutivo.

a) Los legisladores, de manera individual, en forma conjunta pueden presentar proyectos de ley sobre cualquier materia, siempre que ello no implique avanzar sobre atribuciones conferidas exclusivamente al Poder Ejecutivo. 
b) Además del artículo 105 de la constitución de Córdoba, el artículo 144, inciso 3), concede al Poder Ejecutivo la facultad de ser iniciador de proyectos de ley, cuando al referirse a las atribuciones del Gobernador de la provincia, establece expresamente: "Inicia leyes o propone la modificación o derogación de las existentes por proyectos presentados a la Legislatura. Tiene la iniciativa en forma exclusiva para el dictado de las leyes de presupuesto y de ministerios.

c) El artículo 31 de la constitución de Córdoba establece que los ciudadanos pueden proponer a la Legislatura proyectos de ley, delegando en la norma que reglamente este instituto, el porcentaje de firmas que debe contener la solicitud. Establece a su vez que no pueden someterse a este procedimiento, los proyectos relativos a reforma constitucional, aprobación de tratados, tributos, presupuesto y creación y competencia de tribunales.

La constitución de Tucumán le concede iniciativa legislativa al vicegobernador.

2. Los proyectos de ley siguen el esquema de tramitación general, es decir, toman estado parlamentario, son girados a comisión, pueden integrar el Orden del Día. Cuando son tratados por la legislatura, pueden ser aprobados o rechazados. Si es rechazado totalmente no podrá ser nuevamente tratado durante las sesiones de ese año (según artículo 107). De ser aprobados, obtienen sanción definitiva y son remitidos al Poder Ejecutivo, quien los promulgará y publicará o podrá proceder a su veto parcial o total.

Existen determinados proyectos de ley que, para alcanzar el estado de aprobación, requieren de un procedimiento diferente que la Constitución provincial denomina "Doble Lectura". La Carta Magna en su artículo 106 establece cuáles son los proyectos:

Leyes de declaración de reforma de la constitución, el presupuesto general de la provincia, el código tributario, las leyes impositivas, versen sobre empréstitos y otras que la legislatura determine con mayoría absoluta de sus miembros. El procedimiento de doble lectura es el siguiente: De ser aprobado en la primera lectura, se puede afirmar que el proyecto se encuentra "aprobado en primera lectura". En tal caso vuelve a la comisión de origen y, en un plazo no mayor de quince (15) días corridos, lapso durante el cual también puede ser sometido a una audiencia pública, es considerado nuevamente por la Legislatura en pleno. En esta oportunidad o segunda lectura, puede ser aprobado o rechazado. De darse el primer supuesto, obtiene sanción definitiva y es remitido al Poder Ejecutivo para continuar con el trámite normal que requiere cualquier proyecto de ley.

3. Intervención del Gobernador: En virtud de lo establecido en el artículo 109, una vez sancionado el proyecto de ley, pasa al Poder Ejecutivo para su examen, promulgación y publicación. Si el proyecto es sancionado y no vetado dentro de los diez días hábiles de recibida la comunicación por 
el Poder Ejecutivo, queda convertido en ley. Caso contrario si es vetado, totalmente un proyecto vuelve a la Legislatura. Si ésta estuviera conforme, el proyecto queda desechado y no puede repetirse en las sesiones de ese año. Si la legislatura no admitiera el veto podrá insistir en su sanción con el voto de los dos tercios de los miembros presentes, con lo que el proyecto se convierte en ley y pasa al Poder Ejecutivo para su promulgación.

Si es vetado parcialmente el proyecto vuelve a la legislatura. Si ésta estuviera conforme, el proyecto queda convertido en ley con las modificaciones que motivaron el veto. Si son rechazadas las modificaciones por la Legislatura, puede insistir en su sanción con mayoría de los dos tercios de votos de los miembros presentes, con lo que el proyecto se convierte automáticamente en ley y pasa al Poder Ejecutivo para su promulgación.

Si una ley es vetada en parte por el Poder Ejecutivo, éste sólo puede promulgar la parte no vetada si ella tuviere autonomía normativa y no afectare la unidad del proyecto, previa decisión favorable de la Legislatura.

Conforme el artículo 110 de la constitución de Córdoba, en caso de veto de una ley, la legislatura debe tratarla dentro de los treinta días durante las sesiones ordinarias (si estuviere en receso este plazo corre desde la apertura de las sesiones ordinarias o extraordinarias del siguiente año). Transcurrido dicho plazo sin que la Legislatura trate el proyecto, éste queda desechado.

Cuando el órgano legislativo sea bicameral el procedimiento es el siguiente:

1) Toda ley puede tener principio en cualquiera de las cámaras.

2) Aprobado un proyecto por la cámara de su origen, pasará para su revisión a la otra y si ésta también lo aprobase, se comunicará al Poder Ejecutivo para su promulgación.

3) Si la Cámara revisora modifica el proyecto que se le ha remitido, volverá a la iniciadora y si ésta aprueba las modificaciones pasará al Poder Ejecutivo.

4) Si las modificaciones fuesen rechazadas, volverá por segunda vez el proyecto a la cámara revisora y si ella no tuviese dos tercios para insistir, prevalecerá la sanción de la iniciadora.

5) Pero si concurriesen dos tercios de votos para sostener las modificaciones, el proyecto pasará de nuevo a la Cámara de su origen, la que necesitará igualmente el voto de las dos terceras partes de sus miembros presentes, para que su sanción se comunique al Poder Ejecutivo.

6) El Poder Ejecutivo deberá promulgar los proyectos de ley sancionados dentro de diez días de haberle sido remitidos por la legislatura; pero podrá devolverlos con observaciones durante dicho plazo, y si una vez transcurrido no ha hecho la promulgación, ni los ha devuelto con sus objeciones, serán ley de la Provincia y deberán promulgarse y publicarse. 
7) Devuelto un proyecto por el Poder Ejecutivo, será reconsiderado primero en la cámara de su origen, pasando luego a la revisora; y si ambas insisten en su sanción por el voto de los dos tercios de sus miembros presentes, el proyecto será ley y el Poder Ejecutivo se hallará obligado a promulgarlo.

La constitución de Buenos Aires establece que, si un proyecto de ley observado volviere a ser sancionado en uno de los dos períodos legislativos subsiguientes, el Poder Ejecutivo no podrá observarlo de nuevo, estando obligado a promulgarlo como ley.

Constituciones como la de Santa Fe y Buenos Aires si el gobernador no dispone la publicación de la ley sancionada lo podrá hacer el presidente de la cámara que hubiere prestado la sanción definitiva.

\section{CONCLUSIÓN}

Como manifesté a lo largo del presente trabajo la legislatura es un órgano esencial en todo Estado republicano y representativo, ya que es uno de los 3 poderes ejercido por 3 distintos órganos, que cuyas principales funciones son la de legislar sobre las diferentes situaciones jurídicas de la realidad social, intentando regular conductas tanto de personas humanas como también de personas jurídicas, y cubrir amplias lagunas normativas. Otra función principal pero menos distintiva es la de control a los fines de asegurar la igualdad entre los distintos poderes, evitando abusos de poder de uno de ellos.

Además, también el órgano legislativo se destaca por ser un órgano representativo debido a que sus miembros son elegidos por el voto del pueblo, y esto dota el ejercicio de su función de mayor legitimidad y aceptación.

Son órganos que al principio adoptaron la forma organizativa del Congreso de la Nación, siendo esta la bicameralidad y luego del transcurso de los años varias adoptaron la forma unicameralidad debido a las múltiples ventajas que se evidenciaban.

Los legisladores en muchas constituciones gozan de prerrogativas, no solo al ser electos sino antes, al ser considerados candidatos. Estas prerrogativas son otorgadas a los efectos de garantizar el ejercicio independiente de sus funciones.

Que el funcionamiento de los parlamentos está establecido en las constituciones locales o en los reglamentos internos dictados por los mismos cuerpos colegiados, a los efectos de que cumpla su cometido en forma organizada.

Concluyo expresando que, sin importar, los avatares políticos y la composición de la legislatura, ésta debe cumplir su propósito esencial que es la de intentar a través de normas jurídicas, resultado de debates fructíferos y razonables, dar soluciones a problemas que aquejan a los distintos sectores de la sociedad. 